\title{
Caustic Burns in Adults: Epidemiological, Clinical, Endoscopic and Evolutionary Aspects at Sourô Sanou University Hospital Center in Bobo-Dioulasso
}

\author{
Koura Mâli ${ }^{1, ~ *, ~ B a r r o ~ S i e ́ ~ D r i s s a ~}{ }^{1}$, Ouattara Zanga Damien ${ }^{2}$, Zougmore Honoré ${ }^{1}$, \\ Napon/Zongo Passolguewindé Delphine ${ }^{1}$, Zouré Nogogna ${ }^{1}$, Kamboulé Bébar Euloges ${ }^{1}$, \\ Sawadogo Appolinaire ${ }^{1}$ \\ ${ }^{1}$ Department of Medicine, Souro-Sanou University Hospital Centre of Bobo-Dioulasso, Bobo-Dioulasso, Burkina Faso \\ ${ }^{2}$ Department of Medicine, Regional University Hospital Center of Ouahigouya, Ouahigouya, Burkina Faso
}

Email address:

kouramali@yahoo.fr (K. Mâli)

${ }^{*}$ Corresponding author

\section{To cite this article:}

Koura Mâli, Barro Sié Drissa, Ouattara Zanga Damien, Zougmore Honoré, Napon/Zongo Passolguewindé Delphine, Zouré Nogogna, Kamboulé Bébar Euloges, Sawadogo Appolinaire. Caustic Burns in Adults: Epidemiological, Clinical, Endoscopic and Evolutionary Aspects at Sourô Sanou University Hospital Center in Bobo-Dioulasso. Journal of Diseases and Medicinal Plants. Vol. 4, No. 1, 2018 , pp. 30-34. doi: $10.11648 /$ j.jdmp.20180401.14

Received: February 28, 2018; Accepted: March 19, 2018; Published: April 10, 2018

\begin{abstract}
The ingestion of a caustic product is a frequent and sometimes serious accident which can, in the acute phase, bring into play the vital and functional prognosis. The authors report the results of their experiments on 18 cases of caustic ingestion. This was a retrospective descriptive study conducted from February 2012 to January 2016 in the Hepatogastroenterology department of Souro-Sanou University Hospital Centre of Bobo-Dioulasso, Bobo-Dioulasso. All patients over the age of 15 admitted for ingestion of caustics and having undergone upper gastrointestinal endoscopy were included. During the 48-months study period, 18 cases of caustic ingestion were recorded, of which 8 men were a sex ratio of 0.8 . The average age was $31.25 \pm 13.26$ years. Ingestion of caustic was voluntary in 8 out of 10 cases. Ingested product was acidic in $66.67 \%$ of cases. The clinical picture was defined by hematemesis $(50 \%)$ and oral lesions (38.89\%). Endoscopic lesions were dominated by stage IIb (50\%) of ZARGAR. The evolution was marked by a lethality of $11.11 \%$. Caustic burns of the digestive tract are infrequent but serious in our context. Endoscopy plays a very important role in the diagnosis, but their management remains difficult.
\end{abstract}

Keywords: Caustic Burns, Epidemiology, Upper Gastrointestinal Endoscopy, CHUSS-Bobo-Dioulasso, Burkina Faso

\section{Introduction}

In Southern countries, ingestion of caustics is common and constitutes a public health problem in some countries $[1,2]$. It achieves a diagnostic and therapeutic emergency that must be managed in a specialized environment. It causes immediate tissue lesions and variable aspects by direct contact of the corrosive substance with the upper gastrointestinal tract [3] [4]. Initial management must be done in a specialized environment with rapid access to a resuscitation facility (if the clinic requires it) and a suitable technical platform (endoscopy ENT, bronchial, digestive, surgery) [5]. These lesions may evolve favorably towards healing by definitive or negative healing to digestive perforation, cataclysmic haemorrhage with shock or to stenotic and sometimes degenerative sequelae [6].

Endoscopy makes it possible to assess the severity of the lesions and to plan the therapeutic strategy.

The purpose of our work was to report our experience of caustic burns in adults of the upper digestive tract.

\section{Materials and Methods}

\subsection{Type of Study}

It was a retrospective and descriptive study, conducted 
from February 1st, 2012 to January 31st 2016 (48 months) in the Hepato-gastroenterology department of Souro Sanou University Hospital in Bobo-Dioulasso.

\subsection{Study Population and Sampling}

The study population consisted of patients admitted for ingestion of caustics.

The study sample consisted of all patients admitted to the hepatogastroenterology for caustic burns department during the study period.

Only patients who had a high gastrointestinal endoscopy were included.

Children and patients who had ingested products other than caustics were excluded from the study.

\subsection{Variables Studied}

The data collected from medical records and endoscopy reports, focused on the sociodemographic characteristics of patients (age, sex, profession), the nature of the caustic product, the actions taken to evacuate or neutralize the caustic product ingested, the circumstances of ingestion (accidental or voluntary), the existence of psychiatric history, clinical manifestations, endoscopic aspects of the lesions and the therapeutic and evolutionary aspects.

\subsection{Data Collection Technique}

All patients benefited from upper gastrointestinal endoscopy for assessment of initial lesions. However, this examination was not carried out within the recommended time, most often after the 24th hour: either because of delay in the consultation of the patient, or because of the unstable hemodynamic state of this one, or for reasons techniques (digestive endoscopy is performed three times a week).

A radiological assessment was systematic for all patients, and included: an X-ray of the frontal thorax (search for pneumomediastinal complications), and an X-ray of the abdomen without preparation for the search for a pneumoperitoneum.

The therapeutic decision was based essentially on the endoscopic classification of the upper digestive lesions. In the benign lesions corresponding to minor and endoscopic clinical signs revealing a stage I or IIa, the patients had left the hospital the same day. Only patients with an endoscopic stage greater than or equal to grade IIb who have been transferred to the intensive care unit.

The caustic lesions have been described according to the ZARGAR classification (Table 1).

Table 1. ZARGAR classification of caustic burns of the esophagus.

\begin{tabular}{lll}
\hline Stadium 0 & Normal & \\
\hline Stage I & Simple inflammation, edema, hyperemia. \\
& Small ulcerations, focal necrosis, limited. \\
Stage II & Stage IIa & Longitudinal involvement \\
& Stage IIb & Circular infringement \\
& Deep necrosis & \\
Stage III & Stage IIIa & Localized \\
& Stage IIIb & Scope \\
Stage IV & Perforation & \\
\hline
\end{tabular}

\subsection{Data Processing and Analysis}

The data was entered and analyzed using the EPI Info software version 6.0.

The prevalence was calculated by dividing the number of cases of caustic burn admitted during the period by the total number of patients admitted during the same period.

\section{Results}

Characteristics of the population

Among the 3000 cases of hospitalization during the study period, we collected eighteen (18) cases of ingestion of caustic products, achieving a frequency of hospitalization of $0.6 \%$. There were 08 men (44.44\%), a sex ratio of 0.8 . The mean age of the patients was $31.25 \pm 13.26$ years (range: 20 to 56 years). The most represented socio-professional classes were students in 7 cases (38.89\%) and civil servants in 5 cases (27.78\%).

Circumstances of ingestion

Ingestion was voluntary for autolysis in 15 cases $(83.33 \%)$ and accidental in $16.67 \%$ of cases.

In the vast majority of cases $(72.22 \%)$, ingestion was motivated by a psycho-emotional shock, including a disappointment in love. A psychiatric field was found in 2 patients. A first recurrence of attempted autolysis was noted in 1 patient.

Toxicological data

The acids were the most incriminated caustic $(66.67 \%$ of cases), followed by base ( $16.67 \%$ of cases). Almost all the incriminated acids were represented by sulfuric acid $\left(\mathrm{H}_{2} \mathrm{SO}_{4}\right)$. The incriminated bases were exclusively caustic soda $(\mathrm{NaOH})$. Caustics in their liquid form were the most used (88.89\%).

Table 2. Distribution of 18 patients by type of ingested caustic agents。

\begin{tabular}{llll}
\hline \multicolumn{2}{l}{ Nature of the product ingested } & Number of cases & Percentage (\%) \\
\hline \multirow{2}{*}{ Acids } & Sulfuric acid & 11 & 61.11 \\
& Hydrochloric acid & 01 & 5.56 \\
\multirow{2}{*}{ Bases } & Caustic soda & 03 & 16.67 \\
& Indigo & 01 & 5.56 \\
\multirow{2}{*}{ Tother } & Unknown nature & 02 & 11.10 \\
\hline
\end{tabular}

Gestures performed after ingestion of caustic

An attempt to vomit post-ingestion of caustic was reported in 7 cases $(38.89 \%)$. In 05 cases $(2778 \%$ ), milk was administered as an antidote.

Clinical data

Complaints were dominated by hematemesis found in half of the patients (Table 3 ). At the physical examination the oral lesions were noted in 7 patients.

Table 3. Clinical manifestations observed in the 18 patients.

\begin{tabular}{lll}
\hline Signs & Number of cases & Percentage (\%) \\
\hline Hematemesis & $9 / 18$ & 50 \\
Oropharygic lesions & $7 / 18$ & 38.89 \\
Hypersialorrhea & $5 / 18$ & 27.78 \\
Dysphagia & $3 / 18$ & 16.67 \\
Thoracoabdominal pain & $2 / 18$ & 11.11 \\
Asymptomatic patient & $1 / 18$ & 5.56 \\
\hline
\end{tabular}




\section{Radiographic aspects}

The chest X-ray showed the existence of pulmonary pneumonitis in 2 patients. In the rest of the cases, it was normal.

Endoscopic aspects

Upper gastrointestinal endoscopy was normal in 02 (11.11\%) patients. The endoscopic lesions were isolated in the esophagus in 13 cases $(81.25 \%)$ and in 02 cases $(12.5 \%)$ were in the stomach. A lesion $(5.57 \%)$ was located at the esophageal and gastric level.

Table 4. Distribution of the initial endoscopic aspects of the 18 cases of caustic burn.

\begin{tabular}{lll}
\hline Endoscopic stage & Number of cases & Percentage (\%) \\
\hline Stadium 0 & 2 & 11.11 \\
Stage I & 2 & 11.11 \\
Stage IIb & 9 & 50 \\
Stage IIIb & 3 & 16.67 \\
Total ${ }^{*}$ & 16 & 88.89 \\
\hline
\end{tabular}

* $2(11.11 \%)$ patients had aspects of esophageal stenosis at endoscopy.

Therapeutic and evolutionary aspects

Patients with endoscopic stage 0-I lesions (22.22\%) were discharged from hospital after psychiatric consultation and prescription of secretory anti-secretory drugs. Only patients with an endoscopic stage greater than or equal to grade IIb, 14 patients $(77.78 \%)$ were transferred to the intensive care unit. The action to be taken was a hydro-electrolytic reequilibration with resting of the upper digestive tract, administration of antibiotics (amoxicillin-clavulanic acid) and proton pump inhibitors. Parenteral nutrition was based on protein, fat and vitamins. Two patients $(2 / 18)$ received enteral nutrition by jejunostomy. Blood transfusion was performed in 05 patients $(27.78 \%)$. The sequelae consisted of 3 cases of oesophageal stenosis (16.67\%), an annual average of $0.75 \%$ : it was 02 second-hand patients having hidden their ingestion and a patient who was monitored in intensive care. Two (02) deaths (11.11\%) were recorded. Patients with an endoscopic stage IIIb (16.67\%) and sequelae of esophageal stenosis $(16.67 \%)$ were treated surgically.

\section{Discussion}

The limits of the study:

This study has limitations, related in particular:

- the fact that the study sample consists only of adult subjects. Children are excluded, whereas this accident is often more frequent at this age;

- to the type of study that is retrospective here, thus not allowing the collection of certain useful information. For example, variables such as alcohol consumption and family living conditions were lacking;

- the conditions of achievement of upper gastrointestinal endoscopy in our context; who here was most often done after the 24 hour. This introduces a bias for the endoscopic classification of initial lesions that are often maximal beyond the 3rd hour; inadequate case management in an under-resuscitation unit.
The highlights of the study:

- This study is the first of its kind conducted in our hospital, allowed a description of the state of the caustic burns.

- These studies highlight the insufficiency of the technical platform of the resuscitation face caustic burns, thus giving a rough solution for reinforcement.

Epidemiological aspects

In our study, the frequency of hospitalization of caustic burns of the digestive tract was $0.6 \%$ in our department; an average of 4.5 cases per year. The frequency of caustic ingestions is variously reported in the world. In Dakar, Senegal, the prevalence of caustic ingestions is estimated at $1.7 \%$ [7] in a series of adults and children. This accident was at the origin of 483 caustic ingestions from 1997 to 2007 at CHU Kouba of which 236 were adults [8]. The frequency of this incident is 15,000 to 20,000 cases per year in France [9] [10-13]. In the United States, the American Association of Poison Control recorded 206,636 caustic ingestion in 2000 [14] and poison control centers continue to record 15,000 to 26,000 caustic ingestions per year [15-17 ].

The average age of our sample was 31.2 years. This corroborates the literature data that suggests that this is an adult accident. Our results are similar to those reported by other African [8] and Indian [18-19] authors who reported an average age of 27.5 years (25-30 years). The occurrence of caustic burns at this age, can be explained by the frequency of emotional (love disappointment) or professional (end-ofcycle, in search of first job) failures in the majority of cases, in a context of poverty and of psychological immaturity.

We noted a predominance of the female gender $(2 / 3$ of the cases). Similar results are reported by some authors $[8,18]$ [19]. Other authors, on the other hand, [20-22] reported a predominance of the masculine gender. For some African authors, ingestion of caustic is restricted to young girls with no occupation, disadvantaged backgrounds, and housework, making caustic products easily accessible [8, 22]. On the other hand, in our series, pupils / students and civil servants were the most affected social stratum. This layer reported mainly having family and school problems, in addition to the pessimistic speeches of parents, teachers and colleagues.

Toxicological data

Acids and bases were the main caustic agents incriminated in our study. Mourey [15] reported a predominance of oxidants $(38 \%)$, followed by strong bases (34\%) and strong acids such as hydrochloric or sulfuric acid. In our country, there is the free sale in commerce and without regulation caustics such as acids and bases, in this case sulfuric acid (used in the batteries of vehicles) and soda ash (commonly used by women for making soap). A particularity is the case of indigo intoxication which is a substance used in dyeing.

In our study, $88.9 \%$ of the products used were in liquid form. Our results are corroborated by Oumnia [8] who reported that the caustic products involved, in almost all cases, were in liquid form.

Circumstances of ingestion

In our series, $83.33 \%$ of ingestion cases were voluntary. A 
psychiatric note was found in $11.1 \%$ of cases. A disturbed socio-emotional context was noted in $72.22 \%$ of cases. Our results are similar to those of Bouabdellah [23] and Mignonsin [22], which respectively reported voluntary intake frequencies of $72 \%$ and $84.2 \%$. In our opinion, the reasons for these suicide attempts would be related to the difficulties of integration socio-professional, academic failures, academic and emotional young people in a changing society. A society where the traditional family fabric loses itself in the profile of a society that westernizes day after day, with the loss of community values in the profile of individualism. For Fieux [24], an uprooting, isolation, emotional immaturity or a break in psychiatric treatment are frequently noted. For Ait Ouazar [25], the causes of attempted suicide are mainly represented by a "blackmail suicide" in frail, immature subjects where the suicidal gesture takes the value of appeal to the other.

Oumnia [8] in Algeria, however, reported a predominance of accidental ingestions in adults in $64 \%$ of cases. Accidental ingestion in adults is less common in developed countries, is estimated at between 23 and $29 \%$ and is often favored by acute ethyl intoxication, sedatives or other substances [26] [27].

Estimated at 17\%; the frequency of accidental intoxications in our series could be explained in our context, by harmless labeling, dangerous and toxic products are often stored or transferred into vials or bottles for food use.

Gestures achieved after ingestion of the caustic

In our study, $27.78 \%$ of patients had tried to neutralize the product ingested by milk and $38.89 \%$ had caused vomiting. Ignorance of the consequences of attempts to neutralize the caustic product ingested by the patient himself or by his entourage reflects the lack of information of the population and calls for campaigns of education and preventive information.

Clinical aspects

In our series, the dominant symptoms were hematemesis in one out of two cases. Cheng [28], however, reported $4.8 \%$ bleeding episodes in case of adult caustic ingestion in the Chang Gung Memorial Hospital in Tao-Yuang, Taiwan. In our study, oral lesions were present on the examination in $38.9 \%$ of cases. They are usually associated with severe gastroesophageal lesions greater than grade IIb [29]. Some authors note, however, 15 to $25 \%$ of gastroesophageal lesions, without oropharyngeal lesions. [15] [30].

Radiographic aspects

The chest $\mathrm{x}$-ray showed inhalation pneumonitis in two cases $(11.11 \%)$. Our result is identical to that reported by Cheng [28] which was $11 \%$.

Endoscopic aspects

Acute endoscopic lesions were severe in $66.7 \%$ of patients (grade $\mathrm{IIb}=50 \%$, grade $\mathrm{IIIb}=16.67 \%$ ). Since our patients have ingested the strongest acid for the most part, the presence of such serious lesions may seem to contradict the data in the literature according to which acids are less incriminated in the genesis of severe acute lesions with a rate varying between 9 and $18.8 \%[31,32]$. However, in addition to the $\mathrm{pH}$ value, ingested volume and viscosity can be decisive in the genesis of lesions observed in our series. Indeed, a volume of $150 \mathrm{ml}$ of strong acid is considered massive and can cause severe esophageal and / or gastric lesions.

Therapeutic and evolutionary aspects

In our study, patients with an endoscopic stage greater than or equal to grade IIb benefited from resuscitation measures. Indeed, hospitalization in intensive care or resuscitation is necessary when the endoscopy shows stage IIb or IIIa lesions because of the risk of perforation within 48 hours [33]. Antibiotic therapy with amoxicillin-clavulanic acid was used in $77.78 \%$ of our patients. This antibiotic therapy was aimed at treating an infectious syndrome and preventing bacterial contamination of the lesions. In our series, the sequelae consisted of 3 cases of esophageal stenosis in 4 years (16.67\%), an annual average of $0.75 \%$. Mignonsin [22] recorded 6 cases in 7 years at Cocody University Hospital in Côte d'Ivoire (annual average of $0.85 \%$ ).

Overall, the mortality rate after ingestion of caustics varies in the literature from 1.1 to $15.7 \%$ [20, 21, 28, 34]. In our study, the overall mortality of patients was $11.1 \%$, probably related to the severity of caustic lesions sometimes associated with bacterial superinfection.

\section{Conclusion}

Caustic burns of the digestive tract are a reality in our context. In the acute phase, the vital prognosis can be engaged. Endoscopy has a key role, and its use has made it possible to make progress in the diagnosis and management of this pathology. Preventive measures are needed to reduce its prevalence.

\section{References}

[1] Trabelsi M, Loukhil M, Boukhtir S, Hammami M, Bennaceur B. Accidental ingestion of caustics in Tunisian children. About 125 cases. Pediatrics 1990; 45: 801-5.

[2] Contini S, Tesfaye M, Picone P, Pacchione D, Kupper B, Zambianchi $\mathrm{C}$ et al. Corrosive esophageal injuries in children: a short-lived experience in Sierra Leone. Int J PediatrOtorhinolaryngol2007; 71: 1597-1604.

[3] Mathe D, Magret B. Ingestion of caustic material. EMC (Elsevier Masson SAS, Paris), Emergencies 2007; 24-116-A-05.

[4] Hugh TB, Kelly MD. Corrosive Ingestion and Surgeon. Am Coll Surg 1999; 5: 508-22.

[5] Lachaux A, Mas E, Breton A, Barange K, Heresbach D, Molard BR et al. Acta Endosc 2011; 41: 303-308.

[6] Zucchi G. Approach to Clinical Conduct in Caustic Ingestions. Acta Endoscopica 1992; 4: 419-23.

[7] Bassène ML, Diouf ML, Dia D, Mbengue M, Halim A, Diallo S. Digestive caustic lesions: contribution of endoscopy in diagnosis and treatment in the endoscopy center of Aristide Le Dantec University Hospital. J Afr Hepatol Gastroenterol 2012; 6: $179-182$. 
[8] Oumnia N, Lahcene M, Tebaibia A, Matougui N, Boudjella MA, Touchene B. Epidemiology and evolution of caustic burns of the upper digestive tract: about 483 cases. J Afr Hepatol Gastroenterol 2009; 3: 130-6.

[9] Munoz-Bongrand N, Gornat JM, Sarfati E. Diagnostic and therapeutic management of digestive burns by caustics. J Chir $2002 ; 2: 72-3$

[10] Celerier M. Caustic lesions of the esophagus in adults. Ann Chir 2001; 126: 945-9.

[11] Brette MD, Aidan D, Monteil JP. Burns of the esophagus: therapeutic indications. EMC (Paris France), Otorhinolaryngology 1994; 20-820-A- 10; 9 p.

[12] Celerier M. Management of caustic oesophagitis in adults. Ann Chir 1996; 6: 449-55.

[13] Gornet JM. Diagnostic and therapeutic management of digestive burns by caustics. Ileus, 2005, 27, SeptemberOctober.

[14] Ramasamy K, Gumaste VV. Corrosive Ingestion in Adults. J Clin Gastroenterol 2003; 2: 119-24.

[15] Mourey F, Martin L., Jacob L. Caustic burns of the esophagus. conferences discount. Elsevier, Paris, and SFAR 1996 p. 595606.

[16] Bert W, O'Malley JR-MD (1993) Caustic ingestion in children. Baylor College of Medicine Conferences. September 2.

[17] Contrado C. Ingestión de sustanciascorrosivas. Rev Gastroenterol 1998; 18: 3.

[18] Zargar SA, Kochhar R, Nagi B, Mehta S. The role of fiberoptic endoscopy in the management of corrosive and modified endoscopic classification of burns. Gastroenterology 1991; 37: 165-9.

[19] Lahot D, Sohan L, BroorSl, Partha P. Corrosive esophageal strictures: predictors of response to endoscopic dilation. GastrointestEndosc1995; 41: 196-200.

[20] Andreoni B, Marini A, Gavinelli M, Biffi R, Tiberio G, Farina $\mathrm{ML}$, et al. Emergency management of caustic ingestion in adults. A Surg Today 1995; 25: 119-24.

[21] Tohda G, Sugawa C, Gayer C, Chino A, McGuire TW, Lucas CE. Clinical evaluation and management of caustic injury in the upper gastrointestinal tract in 95 adult patients in urban medical center. SurgEndosc2008; 22: 1119-25.
[22] D, Yassibana S, Camara B, Gnionsahe A, Sampson C, Kane M. Caustic Poisoning: An Epidemiological Study and Therapeutic Approach. MedAfr Black 1992; 4: 306-11.

[23] Bouabdellah S, Hannache K, Benmati A, Kellil M, Bouhroum A, Roula D. Epidemiological analysis of causative digestive lesions in adults. J Afr Hepatol Gastroenterol 2012; 6: 264271.

[24] F, Chirica M, Villa A, Losser MR, Cattan P. Ingestion of caustic material in adults. Resuscitation 2009; 18: 606-16.

[25] Ouazar Ait M. Lesions of the digestive tract by ingestion of caustic products. Thesis of Medicine, Morocco, 2007, $\mathrm{n}^{\circ} 74$.

[26] Christesen HB. Caustic ingestion in adults: epidemiology and prevention. J ToxicolClinToxicol 1994; 32: 557-68.

[27] PN Symbas, Vlasis SE, Hatcher CR. Esophagitis secondary to ingestion of caustic material. Ann Thorac Surg 1983; 36: 73-7.

[28] Cheng HT, Cheng CL, CH Lin, Tang JH, YY Chu, Liu NJ et al. Caustic ingestion in adults: the role of endoscopic classification in predicting outcome. BMC Gastroenterology 2008; 31: 7p.

[29] Havanond C, Havanond P. Initial signs and symptoms as prognostic indicators of severe gastrointestinal tract injury due to corrosive ingestion. J Emerg Med 2007; 33: 349-53.

[30] Gaudreault P, Parent M, McGuigan MA, Chicoine L, Lovejoy FH. Predictability of oesophageal injury and symptoms: a study of caustic ingestion in 378 children. Pediatrics 1983; 71: 767-70.

[31] Lee MG, Sing MY, Venugopal S, Spencer H. Caustic strictures of the esophagus. West Indian Med 1990; 39: 245-9.

[32] Christesen HB. Prediction of complication following caustic ingestion in adults. Clin Otolaryngol1995; 20: 272-8.

[33] Pruvot FR, Brami F, Saulnier F, Gambiez L, Roumilhac D, Chambon JP et al. Gastric maintenance in severe caustic lesions of the digestive tract: is it legitimate? Ann Chir2003; 128: 11-7.

[34] Camara BM, Yassibanda S, Camara RF, Mignonin D, Attia YR. Current aspects of caustic esophagitis in tropical hospital settings. Acta endosc 1993; 23: 351-60. 